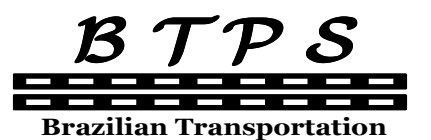

Brazilian Transportation Planning Society
Journal of Transport Literature

Vol. 6, n. 4, pp. 101-132, Oct 2012

Research Directory
JTL | RELIT

www.transport-literature.org ISSN 2238-1031

\title{
Infraestrutura de transporte e crescimento econômico no Brasil
}

[Transport infrastructure and economic growth in Brazil]

\author{
Geovana Lorena Bertussi*, Roberto Ellery Junior \\ Universidade de Brasília (UNB), Brazil, Universidade de Brasília (UNB), Brazil
}

Submitted 12 Sep 2011; received in revised form 2 Dec 2011; accepted 26 Jan 2012

\begin{abstract}
Resumo
0 artigo investiga o impacto dos gastos públicos em transportes sobre o crescimento econômico dos estados brasileiros entre 1986 e 2007 utilizando dados em painel. Além do modelo tradicional de efeitos fixos, optou-se por rodar também um modelo de regressão quantílica. Os resultados obtidos nesse trabalho mostraram que o investimento público no setor de transportes provoca efeito positivo e estatisticamente significante sobre o desempenho econômico de longo prazo dos estados brasileiros e contribui potencialmente para a redução da desigualdade de renda entre eles. Ainda de acordo com as evidências empíricas encontradas, os gastos públicos em infraestrutura de transporte são mais produtivos nas regiões menos desenvolvidas do país (regiões Norte, Nordeste e Centro-Oeste). Dessa forma, mostra-se que as políticas públicas implementadas no país são de extrema relevância para a promoção do crescimento econômico e do desenvolvimento regional brasileiro.
\end{abstract}

Palavras-Chave: crescimento econômico; gastos públicos no setor de transportes; regressão quantílica; dados em painel.

\begin{abstract}
This article intends to investigate the impact of the public spending on transports over the economic growth in the Brazilian states between the years of 1986 and 2007, using panel data. Besides the traditional model of fixed effects, it was also decided to run a quantile regression model. The results of this study showed that public investment in transportation causes positive and statistically significant effect on the long-term economic performance of the Brazilian states and potentially contribute to the reduction of income inequality between them. Also according to the empirical evidence found, public spending on transportation infrastructure is more productive in less developed regions of the country (North, Northeast and Midwest). Thus, the paper shows that public policies implemented in the country are very important for promoting economic growth and regional development in Brazil.
\end{abstract}

Key words: economic growth; public spending on transportation; quantile regression; panel data.

* Corresponding Author. Email: geovanalorena@gmail.com.

\section{Recommended Citation}

Bertussi, G. L. and Ellery Junior, R. (2012) Infraestrutura de transporte e crescimento econômico no Brasil. Journal of Transport Literature, vol. 6, n. 4, pp. 101-132.

- JTL/RELIT is a fully electronic, peer-reviewed, open access, international journal focused on emerging transport markets and published by BPTS - Brazilian Transport Planning Society. Website www.transport-literature.org. ISSN 2238-1031.

This paper is downloadable at www.transport-literature.org/open-access. 


\section{Introdução}

O ajuste fiscal promovido pelo governo federal após a adoção do regime de metas inflacionárias e da imposição de metas de obtenção de superávit primário das contas públicas fez com que se tornassem mais escassos os recursos disponíveis para investimentos em infraestrutura no Brasil. A literatura teórica e empírica, no entanto, ressalta os impactos positivos desses investimentos sobre o crescimento econômico e o desenvolvimento regional. O capital em infraestrutura afeta positivamente o retorno do capital privado já instalado ao aumentar sua produtividade, e ainda cria condições para que novos empreendimentos se tornem atrativos ao reduzir custos de instalação, operação e distribuição. Dentre tais investimentos destacam-se os relativos à infraestrutura de transporte, devido principalmente à extensão do território brasileiro e ao crescimento de seu potencial exportador.

No momento em que o Brasil é apontado como candidato à futura potência econômica e concentra esforços em um Programa de Aceleração do Crescimento (PAC) baseado em investimentos em infraestrutura, torna-se essencial um estudo aprofundado que estime os impactos do aumento da infraestrutura sobre o crescimento econômico do país, assim como sua capacidade de reduzir as desigualdades regionais. Esse conhecimento permite uma avaliação mais criteriosa e embasada na escolha dos projetos beneficiados, sua localização e forma de financiamento.

Nesse sentido, avaliamos o impacto dos gastos públicos em transportes sobre o crescimento econômico dos estados brasileiros entre 1986 e 2007 utilizando dados em painel. Além do modelo tradicional de efeitos fixos, optou-se por rodar também um modelo de regressão quantílica. A motivação para o uso de regressões quantílicas em equações de crescimento está no fato de que o estimador dessa regressão é robusto a observações discrepantes (outliers) da variável dependente (Koenker, 2000; Koenker e Hallock, 2001). Além disso, o estimador de regressão quantílica fornece uma solução para cada quantil da distribuição de renda. Com isso, obtêm-se informações mais específicas de como as variáveis independentes afetam os estados brasileiros de acordo com sua posição na distribuição de crescimento condicional, gerando informações interessantes a respeito da heterogeneidade dos mesmos. Métodos de estimação da média condicional, como o método dos Mínimos Quadrados Ordinários (MQO), 
só podem capturar os efeitos das variáveis explicativas na média da distribuição condicional, o que gera um quadro incompleto.

Os resultados obtidos nesse trabalho mostraram que o investimento público no setor de transportes provoca efeito positivo e estatisticamente significante sobre o desempenho econômico de longo prazo dos estados brasileiros e contribui potencialmente para a redução da desigualdade de renda entre eles. Ainda de acordo com as evidências empíricas encontradas, os gastos públicos em infraestrutura de transporte são mais produtivos nas regiões menos desenvolvidas do país (regiões Norte, Nordeste e Centro-Oeste). Isso significa que a mesma quantidade de gasto público tem impacto diferente dependendo de que região do país ele é aplicado. Dessa forma, mostra-se que o papel do Estado continua a ser de fundamental importância para a promoção do crescimento econômico e o desenvolvimento regional brasileiro.

As seções que se seguem estão organizadas da seguinte forma. A seção 2 traz uma visão geral a respeito do histórico e atual diagnóstico da infraestrutura em transporte no país, bem como uma análise quantitativa e qualitativa dos principais indicadores relacionados aos investimentos em infraestrutura e transportes no Brasil em comparação com alguns outros países do mundo. A seção 3 faz uma revisão da literatura nacional e estrangeira a respeito da relação teórica e estatística entre investimentos em infraestrutura econômica e a taxa de crescimento do produto em diferentes países e regiões do mundo. A seção 4 apresenta os métodos e procedimentos, bem como a descrição dos dados utilizados. Na seção 5 são apresentados e discutidos os principais resultados, enquanto que as conclusões finais são expostas na última seção.

\section{Histórico e atual diagnóstico da infraestrutura em transporte no Brasil}

A literatura econômica aponta o investimento em infraestrutura como um dos principais responsáveis por permitir um crescimento sustentado da economia. Os setores de energia, telecomunicações e transportes têm a capacidade de gerar externalidades positivas, que permitem aumentar a produtividade de outros investimentos e proporcionar ganhos de escala e escopo a outras atividades. Existe, portanto, uma relação de complementariedade entre os investimentos públicos em infraestrutura e o investimento privado (Rigolon, 1998; Pêgo 
Filho, Cândido Jr. e Pereira, 1999). Além disso, de acordo com Macêdo, Nascimento e Kuwwahara (2010), a infraestrutura de transporte constitui-se num diferencial competitivo tanto para as empresas quanto para o governo de um país.

O investimento privado em infraestrutura encontra obstáculos muitas vezes intransponíveis, devido ao pequeno número de grupos empresariais com capacidade financeira para suportar tais desembolsos e os riscos envolvidos nos projetos. Portanto, principalmente em países menos desenvolvidos, que não possuem uma distribuição homogênea da infraestrutura por seu território - como é o caso brasileiro - a participação estatal aparece como alternativa relevante para suprir as necessidades de investimentos. O caso do Brasil torna-se emblemático, pois sua dimensão territorial revela características díspares entre suas regiões, ressaltando a importância dos investimentos em infraestrutura como forma de reduzir essas desigualdades.

A consolidação da infraestrutura em um país com dimensões continentais exige investimentos continuados, consoantes a um plano de desenvolvimento forte e coeso. O Brasil, no entanto, embora não por falta de visão de seus governantes quanto à importância da participação estatal no planejamento e na execução desses planos, não foi capaz de, ao longo das últimas décadas, suprir as necessidades de infraestrutura do país. Para se ter uma idéia, de acordo com estudo realizado pela FGV (2006) em parceria com a União Nacional da Construção, uma comparação entre 200 países para o ano de 2000 revelou que o Brasil apresenta baixo desempenho quanto ao desenvolvimento de sua infraestrutura, ficando atrás de países como Namíbia, Estônia e Hungria no que se refere à extensão da malha rodoviária.

Frischtak (2008) argumenta com base em estudos do Banco Mundial que seria necessário que o Brasil investisse em infraestrutura o equivalente a 3\% de seu Produto Interno Bruto (PIB) apenas para manter o estoque de capital existente. Para alcançar o patamar de países como China e Coréia do Sul, seria necessário investir entre 4\% e 6\% do PIB durante 20 anos. Em 2007, porém, esse investimento foi de apenas $2,01 \%$.

Fica claro a partir disso o papel que tem o setor público no processo de ampliação e desenvolvimento da infraestrutura. No entanto, fatores políticos fizeram e ainda fazem com que a despesa da administração pública com a formação de capital fixo seja descentralizada, sendo grande parte executada por esferas subnacionais. Ademais, Macêdo, Nascimento e 
Kuwahara (2010) argumentaram que a tomada de decisão para realização de investimentos em infraestrutura de transportes é feita de forma superficial pelo governo, que não dispõe de informações e métodos adequados para alocar seus recursos de forma plenamente eficaz. Isso dificulta a conjunção dos investimentos em torno de um planejamento, com uma visão integrada capaz de construir uma infraestrutura eficiente no sentido de facilitar o investimento privado e promover o bem-estar social.

Além disso, a história macroeconômica do Brasil, repleta de períodos turbulentos, contribuiu sobremaneira para que esses objetivos não tenham sido alcançados. Considerando o período analisado neste trabalho, podemos citar logo no início da década de 1980 o grave problema fiscal enfrentado pelo governo federal. Isso provocou um rápido declínio dos investimentos em infraestrutura, que chegaram a superar 10\% do PIB em meados da década de 70 (Pêgo Filho, Cândido Júnior e Pereira, 1999). Em seguida, a partir de 1985, sucessivas tentativas de frear a inflação tornaram o ambiente macroeconômico restritivo quanto aos investimentos, principalmente os privados. Com isso, os investimentos em infraestrutura variaram entre $2 \%$ e 4\% do PIB até meados da década de 90. Ao mesmo tempo países do leste asiático e a China investiam entre 7\% e 9\% de seus PIBs nesses setores (Frischtak, 2008).

Em 1994, um plano econômico bem sucedido foi o principal responsável pela estabilização macroeconômica da economia brasileira. O Plano Real, como foi chamado, trouxe como uma de suas principais premissas a de que a credibilidade das políticas econômicas passa por uma gestão eficaz da dívida pública. Dessa forma, para manter a estabilidade seria necessário equilibrar as contas do governo. Isso impossibilitou um aumento dos gastos com infraestrutura, que no período entre 1994 a 1999 continuaram em patamares entre 1,8\% e 2,8\% do PIB (Silva e Fortunato, 2007).

A segunda metade da década de 1990 foi marcada por grandes dificuldades enfrentadas por países em desenvolvimento em suas economias. A crise da dívida mexicana, que em 1995 colocou em dúvida a condução da política econômica desses países, foi logo seguida pela crise financeira deflagrada no leste asiático em 1997 e pela moratória russa em 1998. Todos esses eventos fizeram com que o Banco Central brasileiro tivesse que manter as taxas de juros internas em patamares extremamente elevados, chegando a $45 \%$ ao ano em março de 1999, o que reduziu drasticamente a atratividade de quaisquer projetos de investimentos no país. 
Depois desse período, o Brasil tomou uma série de medidas com o intuito de tornar a economia do país menos vulnerável a eventos externos que pudessem gerar crises de confiança quanto à condução da política econômica, principalmente no que diz respeito à política cambial. Como resposta à crise - e estrategicamente logo após a reeleição do presidente Fernando Henrique Cardoso em outubro de 1998 - optou-se então por tornar o câmbio flexível. A partir disso, foi necessário recrudescer ainda mais o aperto nas contas públicas, pois a inevitável desvalorização cambial representaria um grande perigo para o controle da inflação no país.

O ajuste fiscal promovido pelo governo federal após a adoção do regime de metas inflacionárias (julho de 1999) e da imposição de metas de obtenção de superávit primário das contas públicas fez com que se tornassem ainda mais escassos os recursos disponíveis para investimentos em infraestrutura no país. Segundo Biasoto Júnior e Afonso (2006), a distribuição do ônus dos cortes de gastos se fez sentir de forma mais abrupta sobre os investimentos em infraestrutura do que nos gastos correntes. A partir do ano de 1999, tais investimentos apresentaram tendência de diminuição, ficando em patamares próximos de $2 \%$ do PIB entre os anos de 2002 e 2007 (Frischtak, 2008).

No início de 2007, diante desse cenário de baixos investimentos em infraestrutura e da necessidade de continuar a incentivar a participação privada, o governo brasileiro lançou o chamado Programa de Aceleração do Crescimento (PAC), prevendo investimentos da ordem de 503,9 bilhões de reais para o período 2007-2010. Para o setor de transportes foi previsto um total de mais de 55 bilhões de reais - aproximadamente $11 \%$ do total do programa distribuídos em diferentes projetos para a construção, modernização, recuperação e integração de rodovias, ferrovias, hidrovias, portos, aeroportos e metrôs em todo o território nacional. No entanto, chama a atenção a distribuição regional desses investimentos. Percebe-se que uma parcela significativa dos recursos beneficiará os estados das regiões sul e sudeste, as mais desenvolvidas do país. Isso deixa claro uma subestimação por parte do governo do potencial redutor das desigualdades regionais dos investimentos em infraestrutura de transportes. Passados mais de quatro anos do lançamento do programa, entretanto, sucessivos cortes de recursos e a morosidade na conclusão dos projetos devem comprometer seu potencial de redução das desigualdades regionais e de integração nacional. 


\subsection{Indicadores de Quantidade e Qualidade: uma Visão Geral}

Durante a década de 1980 a taxa de investimento em infraestrutura no Brasil (como \% PIB) permaneceu próxima de 5\%. Dentre uma amostra de seis países - Argentina, Brasil, Chile, Colômbia, México e Peru - o Brasil foi o país com a maior taxa de investimento em infraestrutura entre 1980 e 1988. A partir de 1989, no entanto, essa taxa caiu para valores abaixo de $3 \%$, e o país foi ultrapassado em performance pelo Chile e pela Colômbia. Durante toda a década de 1990 tanto o Chile quanto a Colômbia foram se distanciando do Brasil e dos demais países do grupo, e chegaram em 2001 com taxas de investimento em infraestrutura da ordem de $6 \%$, mais do que o dobro da taxa observada no Brasil para o mesmo ano e mais do que o triplo da taxa observada na Argentina, no México e no Peru (Calderón e Servén, 2004).

Frischtak (2008) apresentou informações mais atualizadas a respeito da taxa de investimento brasileiro em infraestrutura. Os dados para o período entre 2001 e 2008 podem ser visualizados na Tabela 1:

Tabela 1: Parcela do PIB brasileiro investido em infraestrutura

\begin{tabular}{lc}
\hline Ano & $\%$ PIB \\
\hline 2001 & 3,32 \\
2002 & 2,20 \\
2003 & 1,62 \\
2004 & 1,85 \\
2005 & 2,06 \\
2006 & 2,07 \\
2007 & 2,01 \\
2008 & 2,47 \\
\hline
\end{tabular}

Fonte: Frischtak e Jardim (2009) em estudo para a ABTC

A Tabela 1 mostra que nos últimos anos a taxa de investimento em infraestrutura no país oscilou em torno de 2\%. Em outros países essa taxa foi bem superior. Dados de 2006-2007 para a Índia revelam um investimento em infraestrutura da ordem de 5,63\%. A China em 2003 investiu 7,3\% de seu PIB no setor, enquanto que no mesmo ano o Vietnã investiu 9,9\% e a Tailândia 15,4\% (Frischtak, 2008). 
Dentro dos investimentos em infraestrutura encontram-se os investimentos no setor de transportes. No período entre 2001 e 2008 a parcela do PIB brasileiro investida no setor de transportes foi em média $0,51 \%$. Os dados podem ser vistos na Tabela 2 :

Tabela 2: Parcela do PIB brasileiro investido em transportes

\begin{tabular}{cc}
\hline Ano & $\%$ PIB \\
\hline 2001 & 0,59 \\
2002 & 0,50 \\
2003 & 0,34 \\
2004 & 0,43 \\
2005 & 0,53 \\
2006 & 0,54 \\
2007 & 0,53 \\
2008 & 0,65 \\
\hline
\end{tabular}

Fonte: Frischtak e Jardim (2009) em estudo para a ABTC

Novamente, outros países apresentaram maiores taxas de investimento no setor de transporte do que o Brasil. Dados de 2001 para o Chile e para a Colômbia (considerando apenas os setores rodoviário e ferroviário) revelaram taxas de investimento em infraestrutura de transporte de 1,96\% e 0,89\% respectivamente. Em 2003, as Filipinas investiram 1,2\% do PIB no setor, enquanto a Tailândia investiu 3,9\%, a China 4\% e o Vietnã 6\% (Frischtak, 2008).

Outra constatação importante no caso brasileiro é que a maioria dos recursos investidos no setor de transportes é alocada para o modal rodoviário. No ano de 2001, por exemplo, do total de investimento em transportes, $76 \%$ foi para o subsetor rodoviário. Nos anos seguintes, entre 2002 e 2008, o modal rodoviário abocanhou entre $58 \%$ e $74 \%$ do total de recursos do setor de transportes. Em segundo lugar vem o modal ferroviário, com uma média de 19,5\% do total de gastos em transportes no período compreendido entre 2001 e 2008 (Frischtak, 2008).

Nesse contexto, a matriz do transporte de cargas no Brasil expõe a importância do modal rodoviário para a distribuição das riquezas produzidas internamente. $61,1 \%$ de tudo o que é transportado internamente é levado por meio de rodovias e 20,7\% utilizando-se as ferrovias. Como esses são os modais mais usados para o transporte de cargas, é natural que a maior parte dos investimentos em transporte seja direcionada para esses modais, como constatamos anteriormente. 
Entretanto, o valor médio para se transportar uma tonelada de carga por uma distância de 1000 quilômetros no modal rodoviário é bastante elevado em relação a outros modais, o que aumenta os custos de logística das empresas nacionais, representando um ônus real para todo o país.

Os custos elevados de transporte do modal rodoviário, associado ao fato de que $61,1 \%$ de tudo o que é transportado internamente ser realizado por meio de rodovias, faz com que os custos de logística do país sejam elevados em comparação a outros países. Dados para 2005 revelam que na Rússia, $81 \%$ do transporte de cargas é realizado por meio de ferrovias e somente $8 \%$ por meio de rodovias. Nos Estados Unidos, o modal ferroviário também é predominante, com $43 \%$ do total transportado, seguido pelo modal rodoviário com 32\% (ANTT, 2005). De acordo com o Plano Nacional de Logística e Transportes (PNLT-2007) "essa conformação da matriz de transportes brasileira se traduz em desvantagens comparativas em termos de competitividade internacional de seus produtos de exportação, na medida em que eleva os custos de transporte e impacta negativamente os custos logísticos totais".

Além de apresentar um custo de transporte elevado comparado a outros modais, o modal rodoviário também é um grande poluidor do meio ambiente. De acordo com estudo realizado por Bartholomeu e Caixeta Filho (2008), em 2004 o modal rodoviário foi responsável por $27 \%$ do consumo final de energia brasileira e por $92 \%$ do consumo final de energia do setor de transporte. Ainda segundo os pesquisadores, os índices de poluição do modal rodoviário dependem do estado de conservação das rodovias. Quanto pior o estado das rodovias, maior será o desgaste do veículo no trajeto, o que por sua vez aumenta o consumo de combustíveis fósseis (principalmente o óleo diesel no caso dos caminhões) e a emissão de gás carbônico na atmosfera, gerando maiores custos econômicos e ambientais para o país. A Tabela 3 abaixo mostra a avaliação das rodovias brasileiras para o ano de 2005: 
Tabela 3: Avaliação das rodovias no Brasil em 2005*

\begin{tabular}{lcc}
\hline Estado Geral & Extensão Avaliada $(\mathrm{km})$ & $\%$ \\
\hline Ótimo & 8993 & $10,97 \%$ \\
Bom & 13922 & $16,99 \%$ \\
Deficiente & 26063 & $31,81 \%$ \\
Ruim & 18057 & $22,04 \%$ \\
Péssimo & 14909 & $18,19 \%$ \\
Total & 81944 & $100,00 \%$ \\
\hline Fonte: Confederação Nacional do Transporte (CNT) \\
* Pavimento, Sinalização e Geometria das Rodovias
\end{tabular}

Dentre as rodovias avaliadas, somente cerca de $28 \%$ apresentaram estado geral ótimo ou bom em relação aos quesitos de pavimento, sinalização e geometria da via. A grande maioria $72 \%$ - mostrou-se em deficiente, ruim ou em péssimo estado. Isso evidencia a baixa qualidade da nossa infraestrutura de transporte rodoviário.

É interessante notar que o estado geral das rodovias é bastante diferente entre as regiões geográficas do país. Nas regiões mais desenvolvidas (Sul e Sudeste) a proporção de rodovias em ótimo e bom estado é consideravelmente superior à mesma proporção nas regiões menos desenvolvidas (Norte e Nordeste). A Tabela 4 traz as informações detalhadas para cada região brasileira:

Tabela 4: Avaliação das rodovias - estado geral por região (\%)

\begin{tabular}{lccccc}
\hline Classificação & Norte & Nordeste & Sudeste & Sul & $\begin{array}{c}\text { Centro- } \\
\text { Oeste }\end{array}$ \\
\hline Ótimo & 2 & 2 & 21 & 16 & 7 \\
Bom & 10 & 8 & 15 & 23 & 15 \\
Regular & 43 & 35 & 32 & 41 & 43 \\
Ruim & 35 & 35 & 20 & 15 & 29 \\
Péssimo & 9 & 20 & 12 & 5 & 5 \\
Total & 100 & 100 & 100 & 100 & 100 \\
\hline
\end{tabular}

Fonte: CNT - Pesquisa Rodoviária 2007

As regiões Norte e Nordeste apresentaram respectivamente, para o ano de 2007, somente $12 \%$ e $10 \%$ de suas rodovias em estado ótimo ou bom. Para o mesmo ano, a região Centro-Oeste 
teve $22 \%$ de suas rodovias classificadas como em ótimo ou bom estado de conservação, enquanto que a região Sul teve $39 \%$ e a região Sudeste $36 \%$.

Uma comprovação da baixa qualidade de nossas rodovias é que, de acordo com estudos da Confederação Nacional de Transportes (CNT) para o ano de 2008, somente 11,1\% das estradas brasileiras são pavimentadas. O Brasil tem aproximadamente 1,7 milhões de quilômetros de rodovias e apenas cerca de 200 mil quilômetros são asfaltados. Essa situação coloca o Brasil numa posição muito ruim em relação a outros países. Dados comparativos de 2001 encontrados em Calderón e Servén (2004) mostraram que o Brasil é o pior país latinoamericano nesse quesito, ficando atrás de economias como a Bolívia e o Paraguai. A média dos países latino-americanos é de aproximadamente $20 \%$ de estradas pavimentadas, quase o dobro do registrado no Brasil. Países do leste asiático apresentaram taxa média de pavimentação de suas rodovias acima de $70 \%$ e países industrializados acima de $80 \%$.

Portanto, esse panorama de indicadores de quantidade e qualidade nos permite concluir que o Brasil - comparativamente a outros países - tem uma taxa de investimento agregado baixa, o que leva a baixos investimentos no setor de infraestrutura e, mais especificamente, no setor de infraestrutura de transportes. Ademais, o modal rodoviário é de longe o de maior importância para o transporte de cargas no país, e vimos que esse subsetor apresenta um custo de transporte bastante elevado em relação a outros modais, além de ser altamente poluidor do meio ambiente, devido à queima de combustíveis fósseis. A má conservação das rodovias brasileiras agrava ainda mais a situação, ao contribuir para o aumento de custos econômicos e ambientais.

\section{Revisão de literatura}

Nas últimas duas décadas a discussão teórica e empírica acerca da relação específica entre gastos públicos com infraestrutura, produtividade e crescimento econômico foi estimulada a partir de estudo desenvolvido por Aschauer (1989) para os Estados Unidos no período entre 1949-1985. De acordo com o autor os gastos públicos com infraestrutura (construção de estradas, ruas, aeroportos, saneamento básico, entre outros) foram responsáveis por estimular os ganhos de produtividade de investimentos privados e fomentar o crescimento econômico. Desde então, diversos trabalhos investigaram o impacto dos gastos públicos sobre o desempenho econômico de longo prazo de diferentes países e regiões do mundo e também do 
Brasil, de suas unidades federativas e regiões geográficas. Contudo, esses estudos diferenciam-se com relação ao período analisado, às variáveis explicativas de gasto ou investimento público inclusas no modelo, à técnica econométrica empregada nas estimações, ao nível de agregação dos dados e à abordagem teórica utilizada.

No caso do Brasil, a hipótese de que os gastos públicos com infraestrutura promovem o crescimento econômico foi testada inicialmente por Ferreira (1996). Os resultados evidenciaram uma forte e positiva relação entre os gastos públicos com infraestrutura econômica nos setores analisados e o produto de longo prazo para a economia brasileira. Rigolon (1998) argumenta que os investimentos em infraestrutura são responsáveis por ampliar tanto a quantidade quanto a qualidade ofertada de energia, transporte, telecomunicações e saneamento básico, aumentando a produtividade dos fatores de produção privados e reduzindo os custos por unidade de insumo utilizado, impulsionando dessa forma o crescimento econômico.

Ferreira e Malliagros (1998) realizaram um trabalho empírico bastante completo para a economia brasileira no período entre 1950 e 1995, confirmando algumas estimações realizadas anteriormente no trabalho de Ferreira (1996) e ampliando-as não somente em relação ao horizonte temporal, mas também com respeito ao nível de agregação dos dados. A estimativa a nível agregado indica que um aumento de $10 \%$ no investimento em infraestrutura provocaria uma expansão de 3,9\% no PIB do país. Ao dividirem os investimentos em infraestrutura por setores e repetirem as estimativas, os autores mostraram que a elasticidaderenda do setor de infraestrutura de transportes apresenta valor superior ao do setor elétrico, que por sua vez é maior que a elasticidade do setor de telecomunicações. Dessa forma, os investimentos realizados no setor de transportes têm influência maior na taxa de crescimento do PIB do que os demais setores analisados. Desagregando ainda mais os dados de infraestrutura de transporte, fica clara a maior importância dos investimentos em rodovias em detrimento das ferrovias e portos - para a promoção do crescimento econômico no Brasil.

Cândido Júnior (2001) investigou a relação entre gastos públicos e crescimento econômico no país entre 1947 e 1995 utilizando dados agregados. O modelo estimado dividiu a economia em dois setores: o setor privado e as administrações públicas. Cada um dos dois setores possui uma função de produção própria, sendo que o setor privado tem como insumo o produto do 
setor público. A metodologia empregada permitiu o cálculo da elasticidade-renda do gasto público e também do diferencial de produtividade entre o setor público e privado.

O gasto público foi utilizado em dois conceitos diferentes. A primeira definição de gasto levou em consideração somente o consumo do governo e as transferências. A segunda definição engloba a primeira por acrescentar o investimento das administrações públicas. Para o conceito mais restrito de gasto público, a elasticidade-renda encontrada apresentou sinal negativo. Para o conceito mais amplo, incluindo-se os investimentos, a elasticidade-renda obtida foi positiva e estatisticamente significante igual a 0,43. Além disso, estimou-se que a produtividade do setor público é $40 \%$ menor do que a produtividade do setor privado da economia brasileira.

O autor ainda estimou um modelo auto-regressivo dinâmico para avaliar os efeitos defasados que a política fiscal pode gerar na taxa de crescimento do PIB. Os resultados demonstram que a expansão dos gastos públicos (nas duas definições) estimula a demanda agregada no curto prazo. Porém, no longo prazo o efeito é negativo, ou seja, o gasto público deixa de ser produtivo, pois a necessidade de cobrança de mais impostos para financiar o aumento dos gastos gera distorções na economia que superam os efeitos positivos (externalidades positivas) dos investimentos realizados.

Nessa mesma linha de pesquisa, Arraes e Teles (2001) verificaram o impacto da carga tributária (tamanho ótimo do governo) e da alocação dos gastos governamentais sobre a taxa de crescimento do produto das regiões brasileiras no período entre 1981 e 1995. O resultado alcançado pelos autores está em concordância com o encontrado por Cândido Júnior (2001). Arraes e Teles (2001) utilizaram dados em painel e estimaram um modelo baseado em Barro (1990) com algumas alterações. As estimações revelaram que a carga tributária ideal dos estados brasileiros deveria variar entre $11 \%$ e $15 \%$ do PIB. Entretanto, somente oito estados estavam dentro dessa restrição para o ano de 1995, ou seja, a carga tributária do país é muito elevada, provocando efeitos negativos sobre o crescimento econômico de longo prazo.

Uma vez que a carga tributária é muito elevada e gera externalidades negativas sobre o setor privado da economia, os autores afirmam que duas saídas são possíveis para amenizar o problema: diminuir os gastos públicos ou gastar os recursos de forma mais eficiente. Tendo em vista o segundo propósito, é necessário saber quais tipos de gastos afetam mais 
intensamente a taxa de crescimento das regiões brasileiras, para então direcionar os gastos públicos para seu uso mais produtivo. De acordo com Arraes e Teles (2001), os gastos que apresentaram maior elasticidade-renda são os gastos com educação e cultura, seguidos pelos gastos com infraestrutura de transporte.

Rocha e Giuberti (2005) analisaram o vínculo entre os componentes do gasto público e o crescimento econômico de longo prazo para os estados brasileiros entre 1986 e 2002 utilizando dados em painel. Os gastos do governo foram decompostos - de acordo com sua característica econômica - em gastos correntes e gastos de capital. Considerando-se a classificação funcional, os gastos foram divididos em quatro categorias: defesa nacional, educação, saúde, transporte e comunicação. As autoras fundamentaram suas estimações no modelo de Devarajan et. al. (1996).

As estimações realizadas para diferentes especificações com todos os estados brasileiros apontaram que os coeficientes obtidos para a variável de gastos correntes mostraram-se negativos e estatisticamente significantes. Por sua vez, os coeficientes estimados para a variável de gastos de capital revelaram-se positivos e estatisticamente significantes. As despesas com defesa, educação e transporte e comunicação também apresentaram coeficientes com sinais positivos e significantes. Após essas estimativas iniciais, Rocha e Giuberti (2005) dividiram a amostra de estados brasileiros em dois grupos: estados desenvolvidos (São Paulo, Rio de Janeiro, Minas Gerais, Rio Grande do Sul, Santa Catarina e Paraná) e estados menos desenvolvidos (demais estados restantes) e rodaram novamente o modelo, mas os resultados obtidos não se revelaram fundamentalmente diferentes do alcançado com a amostra global.

Silva e Fortunato (2007) também utilizaram informações desagregadas de gastos públicos em infraestrutura para avaliarem seu impacto sobre a taxa de crescimento de longo prazo dos estados brasileiros. Os autores trabalharam com dados sobre os setores de transporte, energia e telecomunicações no período entre 1985 e 1998. As estimações foram baseadas no modelo de três hiatos engendrado por Bacha (1990).

Inicialmente, os autores estimaram para todas as unidades federativas um modelo no qual a variável dependente era a taxa média de crescimento do PIB per capita nos cinco anos à frente e a variável explicativa era a participação dos gastos públicos em infraestrutura econômica (transportes, energia e telecomunicações) no gasto público total de cada estado. As 
estimações mostraram que existe relação positiva e estatisticamente significativa entre os gastos públicos com infraestrutura econômica e o crescimento do país. Em média, um aumento de $1 \%$ nesses gastos implica numa taxa de crescimento $0,09 \%$ maior. $\mathrm{O}$ mesmo modelo foi estimado, mas agora separando os gastos públicos de infraestrutura econômica em dois tipos: gastos com transporte e gastos com energia e telecomunicações. O coeficiente estimado para gastos com energia e telecomunicações foi positivo e significante, evidenciando uma elasticidade renda de $0,3 \%$ para um aumento de $1 \%$ nesse tipo de gasto. $\mathrm{O}$ coeficiente estimado para gastos públicos no setor de transporte não foi significativo nem mesmo ao nível de $10 \%$.

Assim como Rocha e Giuberti (2005), os autores Silva e Fortunato (2007) dividiram a amostra inicial em dois grupos: regiões desenvolvidas (estados das regiões Sul e Sudeste do país) e regiões menos desenvolvidas (estados das regiões Norte e Nordeste) e os mesmos modelos foram estimados para cada uma das novas amostras. Para as regiões desenvolvidas, a variável de gastos com infraestrutura econômica mostrou-se não significante no primeiro modelo para dados agregados. Desagregando-se os dados, a variável de gastos com energia e telecomunicações apresentou sinal positivo e estatisticamente significante, e o valor estimado do coeficiente foi de 0,5 . Já a variável de gastos em transporte não obteve significância estatística.

Para as regiões menos desenvolvidas o resultado foi bastante diferente. A variável de gastos com infraestrutura econômica foi significante e apresentou valor estimado positivo alto. Um aumento de $1 \%$ nos gastos com infraestrutura econômica aumentaria a taxa de crescimento dos estados menos desenvolvidos em aproximadamente $0,25 \%$. Para o modelo com os gastos decompostos, o coeficiente estimado para a variável de gastos com energia e telecomunicações mostrou-se estatisticamente insignificante. Por sua vez, o coeficiente estimado para gastos em transporte foi positivo e estatisticamente diferente de zero, com valor igual a 0,25. Esse resultado concorda com os estudos de Rocha e Giuberti (2005), que também encontraram impacto mais relevante dos gastos públicos no setor de transporte para as regiões menos desenvolvidas do país, apesar de a divisão de estados desenvolvidos e menos desenvolvidos não ser exatamente a mesma.

Com uma investigação próxima da realizada pelos dois trabalhos citados anteriormente, Silva, Jayme Jr. e Martins (2007) avaliaram a produtividade dos gastos públicos no setor de 
infraestrutura (dados agregados com informações relativas aos setores de transporte, energia e telecomunicações) e de infraestrutura no setor de transportes para o crescimento do produto dos estados brasileiros entre 1986 e 2003. Assim como Silva e Fortunato (2007), as estimações basearam-se no modelo de três hiatos desenvolvido por Bacha (1990).

As diferentes regressões estimadas pelos autores abrangeram sempre todos os estados, não havendo divisão em regiões desenvolvidas e menos desenvolvidas. Os resultados considerando-se as estimações por efeitos fixos - apontaram a importância dos investimentos em infraestrutura como fator promotor do crescimento econômico. Em uma das especificações, um aumento de 10\% dos gastos com infraestrutura econômica (incluindo transportes, energia e telecomunicações) seria responsável por elevar a taxa de crescimento em aproximadamente 1,3\%. Ao trabalhar somente com a variável desagregada de gastos em infraestrutura de transporte, um aumento de $10 \%$ nos gastos em infraestrutura de transporte acarretaria num crescimento do produto da ordem de 1,3\%, em média.

Freitas, Castro Neto e Lôu (2009) estudaram a relação entre gastos públicos e crescimento econômico na região Nordeste do país entre 1987 e 2006 utilizando dados em painel. Eles rodaram um modelo em que a variável dependente é a taxa média de crescimento do PIB no período atual e nos dois períodos seguintes e as variáveis independentes são as despesas correntes e as despesas de capital do governo. A variável de despesa corrente apresentou sinal negativo e estatisticamente significante ao nível de $1 \%$, enquanto que a despesa de capital apresentou coeficiente estimado positivo e estatisticamente significante também ao nível de 1\%. Portanto, o impacto dos gastos públicos sobre o crescimento econômico na região Nordeste depende do tipo de gasto realizado pelo governo, de forma que não é todo tipo de gasto que promove efeito benéfico sobre o crescimento de médio prazo dos estados nordestinos do país. Esse resultado corrobora para a região Nordeste as principais conclusões a que Rocha e Giuberti (2005) chegaram em suas estimativas para os estados brasileiros.

\subsection{Principais resultados da literatura estrangeira}

Barro (1990) elaborou um modelo de crescimento endógeno no qual os gastos públicos entram na função de produção. Partindo de um instrumental simples (os chamados modelos de crescimento endógeno do tipo “AK”), é a presença dos gastos governamentais na função de produção que provoca a característica de retornos constantes de escala. Dessa forma, os 
gastos públicos, ao promoverem externalidades positivas sobre a produtividade do setor privado da economia, gerariam efeitos benéficos para a realização de investimentos nesse setor. Nesse caso, os gastos públicos seriam complementares ao investimento executado pelo setor privado.

Contudo, de acordo com Barro (1990), os efeitos positivos dos gastos públicos sobre a produtividade da economia e sua taxa de crescimento dependerão do tamanho do governo, ou seja, as despesas governamentais originam externalidades positivas até um determinado ponto, a partir do qual o aumento das despesas será responsável por um efeito negativo sobre as taxas de crescimento do produto e da poupança. Esse resultado aparece porque, no modelo desenvolvido, os gastos públicos são financiados por meio de um tributo proporcional à renda, o que acaba por reduzir os recursos disponíveis para o setor privado, diminuindo o potencial de execução dos investimentos.

Easterly e Rebelo (1993), com uma amostra de aproximadamente 100 países para o período entre 1970 e 1988, verificaram que os investimentos públicos são positivamente correlacionados com a taxa de crescimento do produto, e as estimações apresentaram-se robustas. Além disso, os autores afirmam que existe uma relação de complementaridade entre o volume de investimentos públicos e os investimentos privados. Os autores ainda mostraram que existe uma relação estatística robusta e positiva entre os investimentos públicos nos setores de transporte e comunicação e a taxa de crescimento da renda per capita de longo prazo dos países analisados.

Devarajan et al. (1996) investigaram de que maneira a composição do gasto público pode influenciar na taxa de crescimento do produto per capita. Os autores utilizaram dados para 43 países em desenvolvimento (em sua maioria países latino-americanos e africanos) no período entre 1970 e 1990. De acordo com os autores, não seria a quantidade de gastos públicos o fator fundamental para explicar crescimento, mas sim a alocação desses gastos em alternativas mais produtivas. Dessa forma, mesmo que o volume total de gastos públicos permaneça inalterado, ainda assim o crescimento econômico pode ser promovido ao modificarmos a composição das despesas.

O principal resultado do trabalho de Devarajan et al. (1996) foi bastante controverso. Segundo os autores, os gastos públicos correntes apresentaram relação positiva e estatisticamente 
significativa com a taxa de crescimento da renda, enquanto que os gastos públicos de capital apresentaram relação negativa e estatisticamente significante com a mesma variável (variável dependente do modelo). Além disso, ao desagregarem as despesas governamentais em gastos nos setores de saúde, defesa, educação, transporte e comunicação, essas variáveis apresentaram-se estatisticamente significantes com sinal negativo ou mostraram-se estatisticamente iguais a zero (ou insignificantes), o que corroborou os resultados mencionados anteriormente nesse mesmo estudo. É importante ressaltar, no entanto, que as conclusões de Devarajan et al. (1996) contrastaram fortemente com as encontradas em Easterly e Rebelo (1993), sobretudo no que diz respeito à relevância dos investimentos realizados pelo setor público nos setores de transporte e comunicações.

Ainda de acordo com Devarajan et al. (1996), as constatações empíricas de seu trabalho divergiram do estudo de Easterly e Rebelo (1993) por motivos não desprezíveis. No primeiro, a amostra de países analisada pegou exclusivamente países em desenvolvimento, enquanto que no segundo a amostra foi bem grande e diversificada. Para provarem a importância da amostra selecionada, Devajaran et al. (1996) rodaram as mesmas regressões para uma amostra de 21 países desenvolvidos e os resultados foram revertidos, ou seja, o coeficiente estimado para os gastos públicos correntes foi negativo e estatisticamente significante, e o coeficiente dos gastos de capital mostraram-se positivos e estatisticamente significantes. Juntando os dois resultados, os autores afirmaram, então, que os gastos públicos de capital mostraram-se produtivos nos países desenvolvidos, mas improdutivos nos países em desenvolvimento. Além disso, se nos países em desenvolvimento os gastos de capital são pouco produtivos, esses países estariam alocando de forma equivocada as suas despesas ao favorecerem os gastos de capital em detrimento dos gastos correntes.

Também inspirado no trabalho de Devajaran et al. (1996) está a investigação realizada por Ghosh e Gregoriou (2006). Assim como no primeiro artigo, Ghosh e Gregoriou (2006) utilizaram dados anuais para países em desenvolvimento, porém para somente 15 países ${ }^{1}$, no período entre 1972 e 1999. Os autores estimaram um painel dinâmico pelo método dos momentos generalizados (método GMM) e encontraram resultados muito próximos aos obtidos em Devajaran et al. (1996), ou seja, os gastos públicos correntes apresentaram relação

\footnotetext{
${ }^{1}$ Argentina, Brasil, Chile, Colômbia, México, Camarões, Quênia, Sudão, Tanzânia, Zimbábue, Índia, Indonésia, Malásia, Paquistão e Tailândia.
} 
positiva e estatisticamente significante com a taxa de crescimento do produto, enquanto que os gastos públicos de capital mostraram relação negativa e significante com a mesma variável. Gupta et al. (2005) chegaram a resultados inversos para uma amostra de 39 países de baixa renda entre 1990 e 2000.

Morrison e Schwartz (1996) avaliaram o impacto dos investimentos públicos em infraestrutura (rodovias, água e esgoto) para a produtividade de indústrias localizadas em 48 estados norte-americanos no período 1970-1987. As autoras encontraram evidências de que o investimento público em infraestrutura afeta positivamente o crescimento econômico. De acordo com as autoras, a acumulação de capital pelo governo diminui o custo variável das indústrias, aumentando a sua produtividade. Por sua vez, o aumento da produtividade levaria a uma maior taxa de crescimento do produto agregado.

Calderón e Servén (2004) fizeram uma avaliação empírica do impacto da infraestrutura (setores de telecomunicação, energia e transporte) no crescimento econômico e na distribuição de renda para uma amostra de 121 países no período entre 1960 e 2000. Os autores utilizaram medidas de quantidade (volume) e de qualidade, bem como índices agregados e desagregados de infraestrutura. Calderón e Servén (2004) encontraram uma relação positiva e significante entre a quantidade de infraestrutura e a taxa de crescimento do produto per capita de longo prazo das economias. Essa constatação mostrou-se robusta a mudanças nas medidas de infraestrutura utilizadas e a diferentes técnicas de estimação aplicadas. Por sua vez, as evidências apontaram que existe também relação positiva e significante - mas não tão robusta - entre a qualidade de infraestrutura e a taxa de crescimento da renda. Além disso, tanto a qualidade quanto a quantidade de infraestrutura são negativamente correlacionadas - e de forma robusta - com a desigualdade de renda.

\section{Métodos e procedimentos}

Recentes estudos sobre crescimento econômico têm atraído a atenção de economistas de diversas áreas de pesquisa em todo o mundo. Uma das principais preocupações desses cientistas é explicar os fatores determinantes do crescimento de uma economia. Muitos podem ser esses fatores, e existe uma grande variedade de modelos empíricos e teóricos de crescimento que tratam desse assunto e de suas implicações para os formuladores de políticas. Nesse contexto, o presente trabalho investigou a relação entre gastos públicos na área de 
transportes e a taxa de crescimento de longo prazo dos estados brasileiros no período compreendido entre 1986 e 2007, utilizando-se metodologia específica para dados em painel. O modelo estimado pode ser representado pela seguinte equação:

$$
\begin{aligned}
& g_{y i T}=\frac{1}{T} \sum_{T=1}^{5} \ln \left(\frac{Y_{i t+T}}{Y_{i t+T-1}}\right)=\beta_{0}+\beta_{1} \text { tendencia }_{i t}+\beta_{2} \text { GTransport }_{i t}+ \\
& \beta_{3} \text { GTransport } e_{i t}^{2}+\beta_{4} \text { GTotal }+\alpha_{i}+\mu_{t}+\varepsilon_{i t}
\end{aligned}
$$

Em que a variável dependente $g_{y i T}$ é a taxa média de crescimento do PIB per capita do estado $i$ no período $\mathrm{T}$ de cinco anos à frente; tendência tem o objetivo de capturar o progresso tecnológico dos estados brasileiros ao longo dos anos; GTransporte é a participação dos gastos em transporte no gasto total do estado $i$ no período $t$; GTotal é a participação do gasto total (soma das despesas correntes com despesa de capital) no PIB do estado $i$ no período $t ; \alpha_{\mathrm{i}}$ é um efeito específico de unidade federativa e $\mu_{\mathrm{t}}$ é um efeito específico de tempo.

O fato de a variável dependente do modelo ser uma média da taxa de crescimento do PIB per capita dos próximos cinco anos é conseqüência do tempo que gastos públicos em infraestrutura demoram a ser maturados. O impacto de um gasto público na área de infraestrutura de transporte que seja realizado hoje não é imediato. Assim sendo, por uma questão metodológica, nesse trabalho adotou-se os cinco anos à frente como o período em que um investimento realizado hoje terá influência sobre a taxa de crescimento no futuro. Ademais, essa especificação da variável dependente minimiza qualquer problema de endogeneidade e causalidade reversa que esteja presente no modelo, pois a variável dependente e as variáveis explicativas não são contemporâneas.

Os dados de PIB real e PIB real per capita dos estados foram obtidos no Instituto de Pesquisa Econômica Aplicada (IPEA). As informações a respeito dos gastos públicos em transporte e do gasto público total (gastos correntes somados aos gastos de capital) foram extraídas da Execução Orçamentária dos Estados, disponibilizada pelo Tesouro Nacional. Ambas as fontes podem ser acessadas livremente. 
Os dados acima foram selecionados para 25 estados brasileiros e o Distrito Federal. O estado de Tocantins (criado oficialmente em 1989) foi mantido junto com Goiás, devido à indisponibilidade de dados para todo o período estudado, que vai de 1986 a 2007. Além disso, em decorrência da variável dependente do modelo ter sido especificada como a taxa média de crescimento do PIB per capita do estado $i$ no período de cinco anos à frente, então os cinco últimos anos da amostra foram perdidos (2003-2007), de modo que a estimação concentrou-se no período entre 1986 e 2002.

Tendo em vista a natureza dos dados dessa pesquisa e os objetivos inerentes a ela, a forma mais robusta de proceder com a estimação da equação (1) é por meio de um painel de efeito fixo. A principal vantagem desse método é sua habilidade no tratamento de efeitos não observados e variáveis omissas que afetam o crescimento da renda nos diferentes estados brasileiros. Qualquer variável omissa que seja constante ao longo do tempo não afeta a consistência do estimador, mesmo que a variável omissa seja correlacionada com as variáveis explicativas do modelo (por exemplo, fatores históricos e culturais de cada estado). A intuição por trás disso é que todos esses efeitos serão capturados pelo intercepto específico de cada estado $^{2}$. Estimadores de efeito aleatório (EA), entretanto, não seriam adequados aos nossos dados porque assumem que os efeitos não observados individuais sejam distribuídos independentemente das variáveis explicativas.

A equação (1) acima foi estimada quatro vezes. Primeiro estimamos o modelo incluindo todos os estados e o Distrito Federal, para avaliarmos como as variáveis independentes afetam a taxa média de crescimento dos cinco anos à frente no país como um todo. Após essa abordagem inicial, dividimos a nossa amostra de estados brasileiros em dois grandes grupos: um deles formado pelos estados das regiões Norte, Nordeste e Centro-Oeste ${ }^{3}$ (em um total de 18 estados e o Distrito Federal) e outro formado pelos estados das regiões Sudeste e Sul do país ${ }^{4}$ (com um total de 7 estados).

\footnotetext{
${ }^{2}$ De acordo com Durlauf, Johnson e Temple (2004) esse é o principal motivo da utilização do estimador de efeito fixo para estimar regressões de crescimento.

${ }^{3} \mathrm{O}$ grupo formado pelos estados das regiões Norte, Nordeste e Centro-Oeste será chamado de Grupo 1.

${ }^{4} \mathrm{O}$ grupo formado pelos estados das regiões Sudeste e Sul será chamado de Grupo 2.
} 
Considerando-se alguns dos aspectos econômicos e sociais das cinco regiões brasileiras informações a respeito de PIB per capita, taxa de alfabetização, Índice de Desenvolvimento Humano (IDH) e índice de desigualdade de Gini - o primeiro grupo pode ser classificado como subdesenvolvido, enquanto que o grupo formado pelos estados das regiões Sudeste e Sul será classificado como desenvolvido. Com essa repartição, o modelo foi novamente estimado para cada um dos dois grupos.

Separar a amostra inicial dos estados brasileiros em dois grupos distintos permitiu explorar mais pormenorizadamente a relação entre gastos públicos em transporte e a taxa média de crescimento nas diferentes regiões geográficas do país. Finalmente, estimamos a mesma equação utilizando a técnica econométrica de regressão quantílica, o que nos forneceu informações privilegiadas a respeito de toda a distribuição condicional da renda.

\section{Resultados}

A primeira estimação para todas as unidades federativas do país (Tabela 5) mostra que existe uma relação positiva e estatisticamente significante entre os gastos públicos no setor de transportes e a taxa média de crescimento econômico dos estados brasileiros nos cinco anos seguintes. Esse resultado estatístico - ligando maiores gastos públicos a maiores taxas de crescimento da renda - também foi encontrado em diversos outros trabalhos teóricos e empíricos, como Barro (1990), Rigolon (1998), Rocha e Giuberti (2005) e Silva e Fortunato (2007).

O coeficiente estimado negativo e estatisticamente significante ao nível de 5\% para a variável Gtransporte elevada ao quadrado evidencia que existem rendimentos marginais decrescentes na utilização dos recursos públicos no setor de transporte. Isso significa que a mesma quantidade de gasto público tem impacto diferente dependendo de que região do país ele é aplicado. Outra maneira de interpretarmos esse resultado é que os gastos públicos no setor de infraestrutura de transporte tendem a ser mais produtivos nas regiões menos desenvolvidas do país. Uma conseqüência desse argumento é que o governo, muitas vezes, pode não estar realizando seus gastos de maneira eficiente. Em algumas regiões do país, o governo pode estar gastando acima do nível ótimo para alguns setores, enquanto que para outras regiões ocorre o contrário (Cândido Júnior, 2001). 
O efeito da tendência inclusa no modelo é positiva e estatisticamente significante ao nível de 1\%. A variável Gtotal (participação dos gastos totais no PIB de cada estado) não se mostrou significante para explicar o desempenho macroeconômico dos estados brasileiros no período analisado. O poder de explicação do modelo foi de 57,66\%, um valor elevado para estimações por efeito fixo desse tipo de equação. O resultado do modelo desenvolvido nesse artigo está em concordância com os resultados alcançados por Silva, Jayme Jr. e Martins (2007) em sua estimativa que incorpora os gastos públicos no setor de transporte. Entretanto, o modelo desenvolvido pelos autores citados não inclui a variável que capta os rendimentos decrescentes dos gastos públicos em transporte, o que diminui o poder explicativo daquele modelo.

Tabela 5: Gasto público em transporte e crescimento econômico - Brasil

\begin{tabular}{cc} 
Variável Dependente: Taxa de Crescimento do PIB per capita estadual \\
\hline Variáveis Explicativas & Coeficiente Estimado \\
\hline Constante & $-0,0490774$ \\
Tendência & $(-2,13)^{*}$ \\
& 0,0039921 \\
Gtransporte & $(+7,12)^{* *}$ \\
& 0,3443749 \\
Gtransporte & $(+3,51)^{* *}$ \\
& $-0,9199809$ \\
Gtotal & $(-2,06)^{*}$ \\
$\mathrm{R}^{2}$ & 0,0329481 \\
Valor Teste F & $(+0,39)$ \\
Prob > F & 0,5766 \\
Número de Observações & 14,55 \\
* significante ao nível de 5\%; $*$ significante a $1 \%$ & 0,0000 \\
Notas: Estatística t robusta entre parênteses - matriz de covariância consistente a autocorrelação & \\
e heterocedasticidade. & 441 \\
&
\end{tabular}


Após essa análise inicial, estimamos a mesma equação somente para os estados das regiões Norte, Nordeste e Centro-Oeste do Brasil (Grupo 1). Os resultados podem ser vistos na Tabela 6 abaixo. De acordo com as estimações, verifica-se que existe uma relação positiva e estatisticamente significante entre os gastos públicos na área de transporte e a performance econômica dos estados brasileiros pertencentes às regiões menos desenvolvidas do país. A variável Gtransporte elevada ao quadrado apresentou sinal negativo, mas mostrou-se estatisticamente insignificante mesmo ao nível de $10 \%$. Esse resultado sugere que a lei dos rendimentos marginais decrescentes não está agindo para os gastos públicos em transporte nas regiões Norte, Nordeste e Centro-Oeste do Brasil. Uma possível explicação para essa realidade está no fato de que essas regiões ainda estão muito atrasadas em termos de investimentos públicos nas áreas de infraestrutura econômica (transportes, energia e comunicações), o que torna os gastos públicos mais produtivos nessas regiões menos desenvolvidas.

Tabela 6: Gasto público em transporte e crescimento econômico - Grupo 1

\begin{tabular}{cc}
\hline Variável Dependente: Taxa de Crescimento do PIB per capita estadual \\
\hline Variáveis Explicativas & Coeficiente Estimado \\
\hline Constante & $-0,0540118$ \\
Tendência & $(-2,12)^{*}$ \\
& 0,0041307 \\
Gtransporte & $(+5,76)^{* *}$ \\
& 0,3353757 \\
Gtransporte & $(+2,81)^{* *}$ \\
& $-0,757909$ \\
Gtotal & $(-1,32)$ \\
$\mathrm{R}^{2}$ & 0,030702 \\
Valor Teste F & $(+0,35)$ \\
Prob > F & 0,5986 \\
Número de Observações & 14,52 \\
* significante ao nível de $5 \%$ ** significante a 1\% & 0,0000 \\
\hline Notas: Estatística trobusta entre parênteses- matriz de covariância consistente a autocorrelação \\
e heterocedasticidade.
\end{tabular}


O efeito da tendência inclusa no modelo é positiva e estatisticamente significante ao nível de 1\%. A variável Gtotal (participação dos gastos totais no PIB de cada estado) não se mostrou significante para explicar o desempenho macroeconômico das regiões brasileiras menos desenvolvidas no período analisado. O poder de explicação do modelo foi de 59,86\%.

Silva e Fortunato (2007) dividiram a amostra total de estados brasileiros em dois grupos (Norte/Nordeste e Sul/Sudeste) e não incluíram a região Centro-Oeste em nenhum dos grupos estudados, sem justificarem o motivo da exclusão. O modelo desses autores inclui outras variáveis explicativas, porém, a variável de gastos com infraestrutura de transporte apresentou-se com sinal positivo e estatisticamente significante ao nível de $1 \%$ para o grupo Norte/Nordeste, resultado parecido com o encontrado em nosso trabalho. Já para o grupo Sul/Sudeste, os autores encontraram um coeficiente estimado negativo e estatisticamente insignificante para a variável de gastos com infraestrutura de transporte, resultado esse que contrasta com o encontrado aqui. A estimação do modelo para os estados das regiões Sul e Sudeste (Grupo 2) do país pode ser visualizada na Tabela 7.

Tabela 7: Gasto público em transporte e crescimento econômico - Grupo 2

\begin{tabular}{cc}
\hline Variável Dependente: Taxa de Crescimento do PIB per capita estadual \\
\hline Variáveis Explicativas & Coeficiente Estimado \\
\hline Constante & $-0,0164818$ \\
Tendência & $(-1,83)$ \\
& 0,0030151 \\
Gtransporte & $(+6,86)^{* *}$ \\
& 0,2513626 \\
Gtransporte & $(+2,24)^{*}$ \\
& $-1,209352$ \\
Gtotal & $(-2,85)^{* *}$ \\
$\mathrm{R}^{2}$ & 0,084688 \\
Valor Teste F & $(+0,97)$ \\
Prob > F & 0,6634 \\
Número de Observações & 11,46 \\
\hline Notas: Estatística trobusta entre parênteses- matriz de covariância consistente a autocorrelação \\
e heterocedasticidade. * significante ao nível de $5 \% ; * *$ significante a $1 \%$
\end{tabular}


Verifica-se que o coeficiente estimado para a variável Gtransporte é positivo e estatisticamente significante ao nível de 5\%. É interessante ressaltar que o valor desse coeficiente para o Grupo 2 (Sul/Sudeste) é menor do que o coeficiente estimado para a mesma variável no Grupo 1 (Norte/Nordeste/Centro-Oeste), ou seja, um aumento de $1 \%$ nos gastos públicos em transporte em relação aos gastos totais tem impacto diferente nos dois grupos. No Grupo 2 o mesmo aumento percentual dos gastos provoca um crescimento do PIB per capita inferior ao que é observado no Grupo 1. Dito de outra forma, os gastos públicos em infraestrutura de transporte são mais produtivos nas regiões menos desenvolvidas do país. Essa conclusão é compartilhada pelos estudos de Caiado (2002) e de Silva e Fortunato (2007).

Ao contrário do que ocorreu com as regiões Norte, Nordeste e Centro-Oeste, a estimação para as regiões Sul e Sudeste apresentou sinal negativo e estatisticamente significante ao nível de $1 \%$ para a variável Gtransporte elevado ao quadrado. Desse modo, podemos afirmar que para as regiões mais desenvolvidas do país - vigora a lei dos rendimentos marginais decrescentes na utilização dos recursos públicos no setor de infraestrutura de transporte.

Esse resultado traz consigo algumas implicações importantes. Se nas regiões menos desenvolvidas o gasto público em transporte é mais produtivo e, além disso, tem um impacto maior sobre o crescimento econômico de longo prazo, então o papel do Estado na redução das desigualdades regionais do país pode ser crucial. Investindo mais na infraestrutura de transporte das regiões Norte, Nordeste e Centro-Oeste, o Estado pode acelerar o crescimento econômico dessas regiões, gerando um aumento na renda da população, atraindo maiores investimentos privados e diminuindo as disparidades econômicas e sociais com as regiões Sul e Sudeste do Brasil.

A variável de tendência inserida no modelo apresentou-se positiva e estatisticamente significante ao nível de $1 \%$. A variável que representa a participação do gasto total no PIB dos estados brasileiros (Gtotal) revelou-se estatisticamente insignificante. O poder explicativo do modelo é de $66,34 \%$.

De acordo com a estimação via regressão quantílica (Tabela 8), verificamos que os coeficientes calculados para a variável Gtransporte foram positivos e estatisticamente significantes ao nível de $5 \%$ para o primeiro, o terceiro, o quarto e o quinto quantis (ou seja, para os valores de $\theta=0.1,0.3,0.4$ e 0.5$)$. Já para o sexto quantil $(\theta=0.6)$, a variável 
Gtransporte apresentou coeficiente positivo e estatisticamente significativo somente ao nível de $10 \%$. Para os demais quantis o impacto dos gastos públicos em transporte para a taxa média de crescimento do PIB per capita estadual não se mostrou estatisticamente significante. Além disso, os coeficientes estimados foram em média mais altos nos quantis mais baixos de renda, ou seja, para os estados cuja taxa de crescimento da renda per capita é menor (ou menos desenvolvidos) o impacto dos gastos públicos em transporte tende a ser maior que nos estados cuja taxa de crescimento da renda per capita seja maior (ou mais desenvolvidos). Esse resultado está em concordância com nossas estimativas anteriores por meio de efeito fixo.

Ao considerarmos a variável Gtransporte ao quadrado, verificamos que os coeficientes estimados mostraram-se negativos e estatisticamente significantes ao nível de $10 \%$ para $\theta=$ 0.1, 0.5, 0.6 e 0.7. Nos demais quantis não houve a comprovação de significância estatística. $\mathrm{O}$ fato de os coeficiente estimados serem negativos e estatisticamente diferentes de zero para os quantis mencionados indica a presença de rendimentos marginais decrescentes dos gastos públicos em transporte. Além disso, a presença de rendimentos decrescentes ocorre com mais freqüência nos quantis de mais alta renda, novamente um resultado compatível com as nossas estimações anteriores.

A variável Gtotal mostrou-se estatisticamente significante somente para os quantis 0.8 e 0.9 , ou seja, somente para os $20 \%$ de estados brasileiros com maior taxa de crescimento do PIB per capita a variável de participação dos gastos totais no PIB apresentou impacto positivo no crescimento de longo prazo. Para $\theta=0.8$ o coeficiente estimado foi positivo e estatisticamente significante ao nível de $10 \%$, enquanto que para $\theta=0.9$, o coeficiente estimado foi positivo e estatisticamente significante ao nível de $1 \%$. Nas estimativas anteriores - com dados agregados para todas as unidades federativas e com dados desagregados em dois grupos de estados - feitas pela técnica econométrica de efeitos fixos a variável Gtotal não apresentou significância estatística.

Fica clara a importância do método de regressão quantílica nesse contexto, pois essa abordagem permite visualizar como o efeito das variáveis explicativas na taxa de crescimento do produto per capita pode variar ao longo da distribuição de crescimento condicional. Nas estimações por efeito fixo, os coeficientes estimados são os mesmos para todos os estados brasileiros inseridos em cada regressão, de forma que quando uma determinada variável mostra-se não significativa (como no caso de Gtotal), ficamos sem saber se ela é significativa 
para alguma faixa de renda específica dentro do total dos dados utilizados para a estimação. Com a regressão quantílica, percebemos que esse coeficiente médio da variável Gtotal estimado por efeito fixo não é uma boa representação estatística do que ocorre nos $20 \%$ dos estados brasileiros com maior taxa de crescimento da renda per capita.

Conclui-se, então, que a relação positiva e estatisticamente significante entre gastos públicos no setor de transportes e a taxa de crescimento econômico dos estados brasileiros é um fenômeno local, e não uma experiência global ao longo da distribuição condicional. Em particular, averiguamos que, dos nove quantis analisados nesse trabalho, quatro deles não mostraram relação direta entre os gastos públicos em transporte e a taxa de crescimento média da renda per capita no período $(\theta=0.2,0.7,0.8$ e 0.9$)$. Assim sendo, cada grupo de estados brasileiros, ou seja, cada um dos quantis da distribuição condicional, exibe uma dinâmica de crescimento do produto per capita que é diferente dos demais. 
Tabela 8: Gasto público em transporte e crescimento econômico - regressão quantílica

\begin{tabular}{|c|c|c|c|c|c|c|c|c|c|}
\hline \multicolumn{10}{|c|}{ Variável Dependente: Taxa de Crescimento do PIB per capita estadual } \\
\hline Variável/Quantil ( $\theta)$ & 0.1 & 0.2 & 0.3 & 0.4 & 0.5 & 0.6 & 0.7 & 0.8 & 0.9 \\
\hline \multirow[t]{2}{*}{ Constante } & $0.04968 * *$ & $0.03911 *$ & 0.02802 & 0.02183 & 0.03048 & 0.02470 & 0.03567 & 0.04170 & $0.05238 *$ \\
\hline & $(-2.20)$ & $(-1.69)$ & $(-1.16)$ & $(-0.89)$ & $(-1.46)$ & $(-1.09)$ & $(-1.61)$ & $(-1.57)$ & $(-1.76)$ \\
\hline \multirow[t]{2}{*}{ Tendência } & $0.00463 * * *$ & $0.00425^{* * *}$ & $0.00413 * * *$ & $0.00368 * * *$ & $0.00349 * * *$ & $0.00288^{* * *}$ & $0.00295^{* * *}$ & $0.00270 * * *$ & $0.00228 * * *$ \\
\hline & $(6.60)$ & $(5.54)$ & $(6.74)$ & $(6.26)$ & $(6.04)$ & $(4.89)$ & $(5.92)$ & $(5.45)$ & $(4.03)$ \\
\hline \multirow[t]{2}{*}{ Gtransporte } & $0.23280^{* *}$ & 0.16556 & $0.21386^{* *}$ & $0.22665^{* *}$ & $0.21620^{* *}$ & $0.19965^{*}$ & 0.16519 & 0.15488 & 0.09963 \\
\hline & $(2.16)$ & $(1.44)$ & $(2.10)$ & (1.99) & (1.99) & $(1.81)$ & $(1.45)$ & $(1.22)$ & $(0.72)$ \\
\hline \multirow[t]{2}{*}{ Gtransporte2 } & $0.98901 *$ & 0.42799 & 0.48108 & 0.71781 & $0.87142 *$ & $0.93087^{*}$ & $0.90947 *$ & 0.95097 & 0.96611 \\
\hline & $(-1.70)$ & $(-0.78)$ & $(-1.07)$ & $(-1.34)$ & $(-1.80)$ & $(-1.84)$ & $(-1.76)$ & $(-1.54)$ & $(-1.44)$ \\
\hline \multirow[t]{2}{*}{ Gtotal } & 0.01364 & 0.01453 & 0.03381 & 0.02361 & 0.03617 & 0.06276 & 0.12366 & $0.16605 *$ & $0.26390 * * *$ \\
\hline & $(-0.16)$ & $(-0.18)$ & $(-0.43)$ & $(-0.29)$ & $(0.48)$ & $(0.78)$ & (1.40) & (1.76) & $(2.59)$ \\
\hline Pseudo $\mathrm{R}^{2}$ & 0.4945 & 0.4208 & 0.3897 & 0.3781 & 0.3869 & 0.3985 & 0.4147 & 0.4562 & 0.5486 \\
\hline
\end{tabular}

Notas: $*$ significante ao nível de $10 \% ; * *$ significante a $5 \% ; * * *$ significante a $1 \%$

Estatística t entre parênteses (erro padrão obtido por meio de bootstrap com 1000 replicações)

Pseudo R é uma estatística, desenvolvida por Koenker e Machado (1999), análoga ao coeficiente global de determinação R tradicional, mas que mensura o grau de ajustamento local para cada um dos quantis da distribuição condicional.

Resultados relativos à estimação da equação (1), onde controlamos pelos efeitos específicos de estado e de tempo. 


\section{Conclusão}

O presente trabalho investigou a relação entre gastos públicos na área de transportes e a taxa de crescimento dos estados brasileiros no período entre 1986 e 2007, utilizando-se duas metodologias distintas: uma específica para estimação com dados em painel (estimação por efeitos fixos), e outra estimação inédita por meio de regressão quantílica.

Os resultados obtidos pelas estimações de efeito fixo mostraram que o investimento público no setor de transportes provoca efeito positivo e estatisticamente significante sobre o desempenho econômico dos estados brasileiros e contribui potencialmente para a redução da desigualdade de renda entre eles. Ainda de acordo com as evidências empíricas encontradas, os gastos públicos em infraestrutura de transporte são mais produtivos nas regiões menos desenvolvidas do país (regiões Norte, Nordeste e Centro-Oeste), comparando-se com as regiões mais desenvolvidas (Sul e Sudeste). Isso significa que a mesma quantidade de gasto público tem impacto diferente dependendo de que região do país ele é aplicado.

Considerando-se a estimação por regressão quantílica, as evidências descobertas corroboraram os resultados encontrados anteriormente. Entretanto, a relação positiva e estatisticamente significante entre gastos públicos no setor de transportes e a taxa de crescimento econômico dos estados brasileiros é um fenômeno local, e não uma experiência global ao longo da distribuição condicional. Em particular, averiguamos que, dos nove quantis analisados nesse trabalho, quatro deles não mostraram relação direta entre os gastos públicos em transporte e a taxa de crescimento média da renda per capita no período $(\theta=0.2,0.7,0.8$ e 0.9). Assim sendo, cada grupo de estados brasileiros, ou seja, cada um dos quantis da distribuição condicional exibe uma dinâmica de crescimento do produto per capita que é diferente dos demais.

Tomando como base os resultados obtidos nesse estudo, podemos concluir que o papel do Estado continua a ser de fundamental importância para a promoção do crescimento econômico e o desenvolvimento regional brasileiro. Investindo mais na infraestrutura de transporte das regiões Norte, Nordeste e Centro-Oeste, o Estado pode acelerar o crescimento econômico dessas regiões, gerando um aumento na renda da população, atraindo maiores investimentos privados e diminuindo as disparidades econômicas e sociais com as regiões Sul e Sudeste do Brasil. 


\section{Referências}

Afonso, J. R. R. e G. Biasoto (2006) Oferta de infraestrutura e desenvolvimento econômico: os desafios do investimento público no Brasil. In: Teixeira, E. e M. Braga (org.). Investimento e crescimento econômico no Brasil. Viçosa: Universidade Federal de Viçosa, p. 131-17.

Arraes, R.A. e V.K. Teles (2001) Política Fiscal e Crescimento Econômico: Aspectos Teóricos e Evidências Empíricas para as Regiões Brasileiras. Revista Econômica do Nordeste, Fortaleza, v. 32, n. Especial, p. 676-690.

Aschauer, D. (1989) Is public expenditure productive? Journal of Monetary Economics, v. 23, p. 177200.

Bacha, E. L. (1990) A three-gap model of foreign transfers and the GDP growth rate in developing countries. Journal of Development Economics. n. 32, p. 279-296.

Barro, R. (1990) Government Spending in a Simple Model of Endogenous Growth. Journal of Political Economy, v. 98, p. 103-125.

Bartholomeu, D. B. e J.V. Caixeta Filho (2008) Impactos econômicos e ambientais decorrentes do estado de conservação das rodovias brasileiras: um estudo de caso. Revista de Economia e Sociologia Rural, v.46, n. 3, p. 703-738.

Caiado, A. S. C. (2002) Desconcentração industrial regional no Brasil (1985 - 1998): pausa ou retrocesso? Tese de Doutorado, IE-UNICAMP.

Calderón, C. e L. Servén (2004) The effects of infrastructure development on growth and income distribution. Policy Research Working Paper Series 3400, The World Bank.

Calderón, C. e L. Servén (2004) Trends in Infrastructure in Latin America, 1980-2001. World Bank Policy Research Working Paper No. 3401.

Cândido Júnior, J. (2001) Os gastos públicos no Brasil são produtivos? IPEA, Texto para Discussão no. 781.

Devarajan S.; V. Swaroop e H.F. Zou (1996) The Composition of Public Expenditure and Economic Growth. Journal of Monetary Economics, Vol. 37, pp. 313-344.

Durlauf, S. N.; P. A. Johnson e J. R.W. Temple (2004) Growth econometrics. Poughkeepsie: Vassar College Economics. 183p. (Working Paper, 61).

Easterly, W. e S. Rebelo (1993) Fiscal Policy and Economic Growth: An Empirical Investigation, Journal of Monetary Economics, Vol. 32, 417-458.

Ferreira, P.C. (1996) Investimento em Infraestrutura no Brasil: fatos estilizados e relações de longo prazo. In: Pesquisa e Planejamento Econômico. 26 (2), 231-252.

Ferreira, P. C. e T.G. Malliagros (1998) Impactos Produtivos da Infraestrutura no Brasil - 1950/95. Pesquisa e Planejamento Econômico. 28 (2), 315-338.

FGV (2006) - A Construção do Desenvolvimento Sustentado: A importância da construção na vida econômica e social do país. Parceria com a União Nacional da Construção - FGV Projetos. São Paulo, agosto, $44 \mathrm{p}$.

Freitas, U.R.P; A.A. Castro Neto e I.C. Lôu (2009) Relação entre Gastos Públicos e Crescimento Econômico: uma Análise com Dados em Painel para o Nordeste. Conjuntura e Planejamento, $\mathrm{n}$. 162 , p. $50-57$.

Frischtak, C.R. (2008) O Investimento em Infraestrutura no Brasil: Histórico Recente e Perspectivas. Pesquisa e Planejamento Econômico, v.38, n.2, p.307-348. 
Ghosh, S. e A. Gregoriou (2006) On the Composition of Government Spending, Optimal Fiscal Policy, and Endogenous Growth: Theory and Evidence, Brunel Economics and Finance Working Paper 06-19.

Gupta, S.; B. Clements; E. Baldacci e C. Mulas-Granados (2005) Fiscal Policy, Expenditure Composition, and Growth in Low- Income Countries, Journal of International Money and Finance, 24, 441-463.

Koenker, R. (2000) Quantile regression. In: FIENBERG, S.; KADANE, J. (Ed.) International Encyclopedia of the Social Science: statistics section. [s.1.]: [s.n.].

Koenker,R. e K. Hallock (2001) Quantile regression. Journal of Economic Perspectives, Nashville, Tenn., v. 15, n. 4, p. 143-156.

Macêdo, C. S; J.C. Nascimento e N. Kuwahara (2010) Estudo comparativo da análise hierárquica com multiobjetivo para seleção de projetos públicos de investimento em infraestrutura de transporte. Revista Transportes, v. XVIII, n. 2, p.46-52.

Morrison, C.J. e A.E. Schwartz (1996) State Infrastructure and Productive Performance, The American Economic Review, v.86, n.5, pp. 1095-1111.

Pêgo Filho, B.; J.O. Cândido Jr e F. Pereira (1999) Investimento e Financiamento da Infraestrutura no Brasil: 1990/2002, IPEA, TD, 680, Brasília.

Programa de Aceleração do Crescimento (PAC) (2007) - Ministério da Fazenda.

Rigolon, F. (1998) O investimento em infraestrutura e a retomada do crescimento econômico sustentado. Pesquisa e Planejamento Econômico, v.28, n.1, p.129-158.

Rocha, F. e A.Giuberti (2005) Composição do Gasto Público e Crescimento Econômico: um estudo em painel para os estados brasileiros. Anais do XXXIII Encontro Nacional de Economia, Natal, RN.

Silva, G.J.C. e W.L.L Fortunato (2007) Infraestrutura e Crescimento: Uma Avaliação do Caso Brasileiro no Período 1985-1998. In: Fórum BNB de Desenvolvimento XII Encontro Regional de Economia, Fortaleza.

Silva, G. J. C.; F.G. Jayme Jr e R.S Martins (2007) Gasto Público com Infraestrutura de Transporte e Performance dos Estados Brasileiros: 1986-2003. (mimeo). 